See discussions, stats, and author profiles for this publication at: https://www.researchgate.net/publication/326322922

\title{
An international program on Silk Road Disaster Risk Reduction-a Belt and Road initiative (2016-2020)
}

Article in Journal of Mountain Science · July 2018

DOI: $10.1007 / 511629-018-4842-4$

\section{CITATIONS}

8 authors, including:

C

Institute of mountain hazards and environment

9 PUBLICATIONS 70 CITATIONS

SEE PROFILE

2. Virginia Murray

Public Health England

177 PUBLICATIONS 3,263 CITATIONS

SEE PROFILE
READS

246

7. Amar Deep Regmi

Chinese Academy of Sciences

32 PUBLICATIONS 581 CITATIONS

SEE PROFILE

Giacomo Titti

University of Bologna

4 PUBLICATIONS OCITATIONS

SEE PROFILE

Some of the authors of this publication are also working on these related projects:

Sino-Italian Joint Lab on Geological and Hydrological Hazards of Belt and Road Initiative View project

Health Emergency and Disaster Risk Management (Health-EDRM) View project 


\section{An international program on Silk Road Disaster Risk Reduction - a Belt and Road initiative (2016-2020)}

LEI Yu1,2 iD http://orcid.org/oooo-ooo2-2224-326o; e-mail: leiyu@imde.ac.cn CUI Peng1,3* iD http://orcid.org/oooo-0oo2-3973-5966; e-mail: pengcui@imde.ac.cn Amar Deep REGMI1 iD http://orcid.org/oooo-0oo2-1423-9990; e-mail: amardeep_regmi@yahoo.com Virginia MURRAY4,5 iD http://orcid.org/oooo-00o3-4746-4024; e-mail: Virginia.Murray@phe.gov.uk Alessandro PASUTO6 (D http://orcid.org/oooo-00o2-9926-9581; e-mail: alessandro.pasuto@irpi.cnr.it Giacomo TITTI6 (D)http://orcid.org/oooo-ooo3-1980-8723; e-mail: giacomo.titti@irpi.cnr.it Muhammad SHAFIQUE7 (D) http://orcid.org/oooo-0oo2-4063-6666; e-mail: shafiqueo8@yahoo.com Tilak PRIYADARSHANA D. G. 8 iD http://orcid.org/oooo-ooo2-9156-798X; e-mail: tilakgamage@gmail.com

${ }^{*}$ Corresponding author

1 Key Laboratory of Mountain Hazards and Earth Surface Processes/Institute of Mountain Hazards and Environment, Chinese Academy of Sciences, Chengdu 610041, China

2 University of Chinese Academy of Sciences, Beijing 10oo49, China

3 CAS Center for Excellence in Tibetan Plateau Earth Sciences, Beijing 100101, China

4 Public Health England, London 133-155, England; UNISDR Scientific and Technical Advisory Group, Geneva, Switzerland

5 Integrated Research on Disaster Risk Scientific Committee, Beijing 10oo94, China

6 Research Institute for Geo-Hydrological Protection, National Research Council, 4- 35127 Padova, Italy

7 National Center of Excellence in Geology, University of Peshawar, Peshawar 2513o, Pakistan

8 Internal Quality Assurance Unit \&Center for International Affairs, University of Ruhuna, Matara, Sri Lanka

Citation: Lei Y, Cui P, Regmi AD, et al. (2018) An international program on Silk Road Disaster Risk Reduction - a Belt and Road initiative (2016-2020). Journal of Mountain Science 15(7). https://doi.org/10.1007s11629-018-4842-4

(C) Science Press, Institute of Mountain Hazards and Environment, CAS and Springer-Verlag GmbH Germany, part of Springer Nature 2018

\begin{abstract}
Belt and Road Initiative (BRI) is a Chinese national strategy which calls for cooperative economic, political and cultural exchange at the global level along the ancient Silk Road. The overwhelming natural hazards located along the belt and road bring great challenges to the success of BRI. In this framework, a 5-year international program was launched to address issues related to hazards assessment and disaster risk reduction (DRR). The first workshop of this program was held in Beijing with international experts from over 15 countries. Risk conditions on Belt and Road Countries (BRCs) have been shared and science and technology
\end{abstract}

Received: 12 January 2018

Revision: 05 May 2018

Accepted: 15 June 2018 advancements on DRR have been disseminated during the workshop. Under this program, six task forces have been setup to carry out collaborative research works and three prioritized study areas have been established. This workshop announced the launching of this program which involved partners from different countries including Pakistan, Nepal, Russia, Italy, United Kingdom, Sri Lanka and Tajikistan. The program adopted the objectives of Sendai Framework for Disaster Risk Reduction 20152030 and United Nation Sustainable Development Goals 2030 and was implemented to assess disaster risk in BRCs and to propose suitable measures for disaster control which can be appropriate both for an individual country and for specific sites. This paper deals with the outcomes of the workshop and points 
out opportunities for the near future international cooperation on this matter.

Keywords: Natural hazards; Silk Road; Disaster risk reduction; Belt and Road Initiative; Sendai Framework; International collaboration program

\section{Introduction}

The Silk Road Economic Belt and the 21stcentury Maritime Silk Road, also known as the Belt and Road Initiative (BRI), was first proposed by Chinese President Xi Jinping during his visit of Central Asia and Southeast Asia in 2013 and since then have attracted close attention from all over the world. The idea of BRI derived from the ancient Silk Road which served as a major route for trade and culture exchange between countries in Asia, Europe and Africa (Elisseeff 1998). In March 2015, National Development and Reform Commission (NDRC), Minister of Foreign Affairs (MFA) and Minister of Commerce (MC) of China issued 'Vision and Actions on Jointly Building the Belt and Road' (Vision and Actions 2015). BRI is a call for inclusive globalization which aims to promote the orderly and free flow of economic factors, efficient allocation of resources and deep integration of markets by enhancing connectivity of Asian, European and African continents and their adjacent seas. In terms of facilities connectivity, the BRI prioritizes six major land transport corridors (Figure 1): a new Eurasian Land Bridge, ChinaMongolia-Russia, China-Central Asia-west Asia, China-Pakistan, China-Indochina and BangladeshChina-India-Myanmar ( $\mathrm{Liu}$ et al. 2015, 2016). Among these, the China-Pakistan Economic Corridor (CPEC) is currently under construction. Transport infrastructures in Belt and Road Countries (BRCs) are therefore one of the main objectives of BRI. In this framework, natural hazards represent one of the major challenges which would affect the safety, durability and accessibility of such infrastructures. Therefore, assessment of main hazards and application of effective measures to reduce the risk along the Belt and Road is of paramount importance for the success of BRI.

In September 2016, the Chinese Government announced the prioritization of research areas regarding the implementation of BRI. The present project "Silk Road Disaster Risk Reduction (SiDRR)" was established within such prioritized areas and is funded by the Chinese Academy of Science. It aims to identify the major natural hazards in the BRCs, to study their triggering and development mechanisms, to understand their evolution, forecast major disaster occurrences and protect the infrastructures along the Belt and Road corridors. At the same time, the project intends to create a disaster reduction framework which links research facilities from different countries thus promoting international cooperation to create more efficient and active DRR platform.

2015 was a remarkable year for the United Nations (UN) as 3 landmark agreements were finalized and adopted by the UN member states. These agreements are the Sendai Framework for Disaster Risk Reduction 2015-2030, the Sustainable Development Goals and the Paris Agreement on the Climate Change. The Sendai Framework aims to achieve the following outcome over the next 15 years:

"The substantial reduction of disaster risk and losses in lives, livelihoods and health and in the economic, physical, social, cultural and environmental assets of persons, businesses, communities and countries" (UNISDR 2015).

The implementation of the Sendai Framework for Disaster Risk Reduction 2015-2030 (UNISDR 2015) has seven global targets, which are:

(1) Substantially reduce global disaster mortality by 2030 , aiming to lower the average per 100,000 global mortality rate in the decade 20202030 compared to the period 2005-2015;

(2) Substantially reduce the number of affected people globally by 2030, aiming to lower the average global Figure per 100,000 in the decade 2020-2030 compared to the period 20052015;

(3) Reduce direct disaster economic loss in relation to global gross domestic product (GDP) by 2030;

(4) Substantially reduce disaster damage to critical infrastructure and disruption of basic services, among them health and educational facilities, including through developing their resilience by 2030;

(5) Substantially increase the number of countries with national and local disaster risk reduction strategies by 2020; 


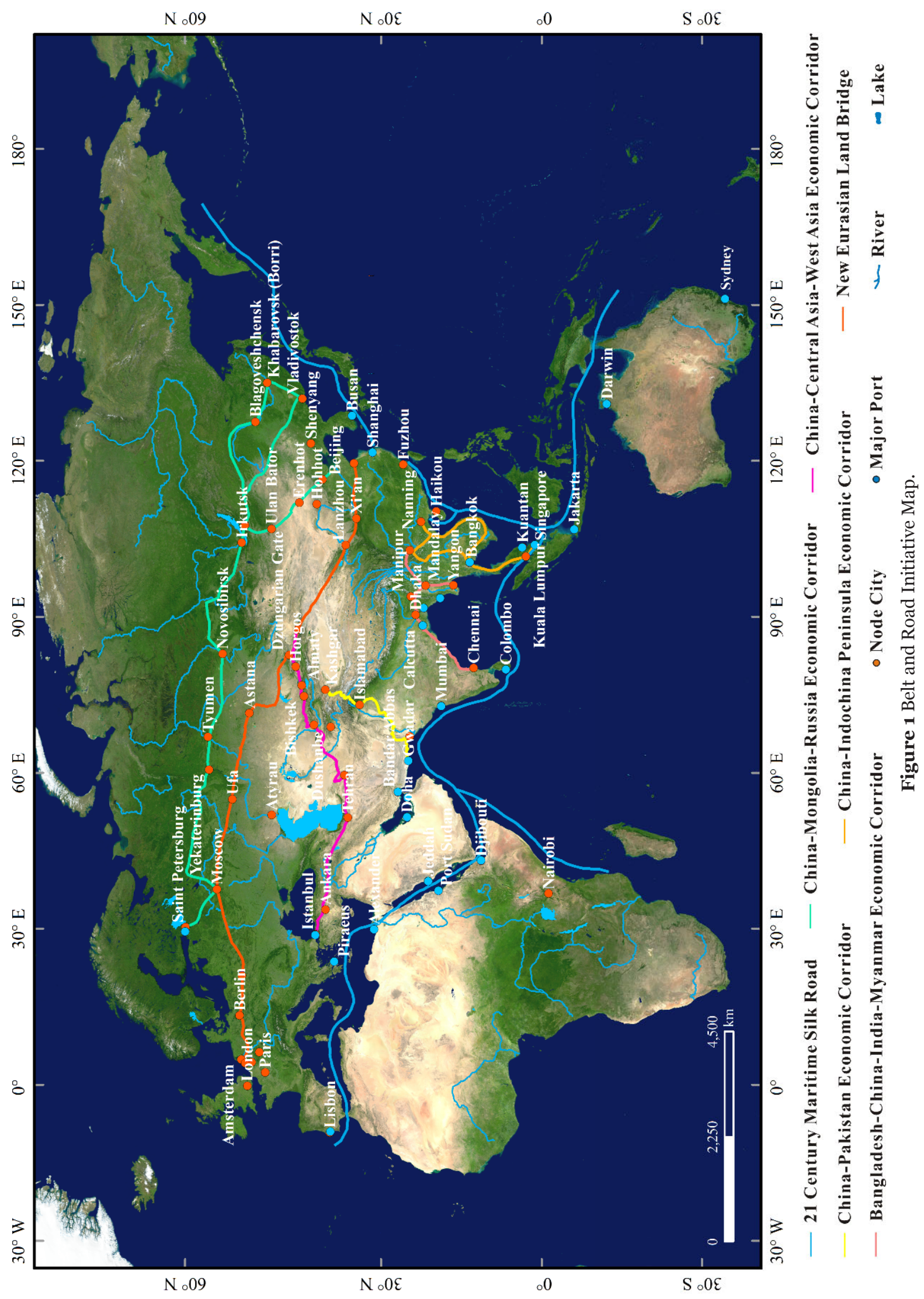


(6) Substantially enhance international cooperation to developing countries through adequate and sustainable support to complement their national actions for implementation of the present Framework by 2030;

(7) Substantially increase the availability of and access too multi-hazard early warning systems and disaster risk information and assessments to people by 2030.

In Summary, the main agenda of the UN landmark frameworks include the reduction of disaster risks and losses of life and property, improves health and education, and combats climate change for a sustainable development.

The Belt and Road Initiative shares the same vision and provides opportunities and resources to the BRCs for economic and social development in a sustainable way. The main task of reducing natural hazards impact on BRCs complements the priorities for action of the Sendai Framework for DRR and would also help on the implementation of a shared international platform for disaster reduction in BRCs.

\section{Background on Natural Hazards in BRCs}

The extremely large area covered by BRI results in a wide range of morphological setting thus associated with different types of natural hazards affecting BRCs. In the first phase of this project, four types of natural hazards will be taken into consideration. They are:

(1) Geophysical: Earthquake

(2)Geo-Hydrological: Landslide, Flood, Debris flow

(3)Coastal: Tsunami, Wave action

(4)Climatological: Drought, Glacial lake outburst

These natural hazards are closely related to the geological and morphological conditions of the considered areas. A summary of BRCs with their associated natural hazards are put together in Appendix 1. South East Asian countries are mostly flat with few small reliefs. Therefore, they mostly suffer from flooding and earthquakes but some landslides have also been recorded in these countries (Appendix 1). Central and western Asia is mostly flat but some countries are mountainous. The natural hazards here are dominated by floods and landslides with some earthquakes. Most of the South Asian countries belong to high mountain ranges such as the Himalaya, Hindu Kush and Karakoram. Due to their rough terrain, they mostly suffer from mountain hazards like landslides, debris flows, glacial lake outburst floods (GLOF) and earthquakes. Other countries in the region, such as Bangladesh and Southern part of India are affected by floods. The Middle East and African countries are more prone to earthquakes, floods and droughts. Central and Eastern Europe being mostly flat land are frequently affected by the flood. European countries within Alps range also suffer from landslides, debris flows, flash floods, earthquakes and GLOF (Appendix 1).

As a result of climate change, rapid unplanned urbanization and other human activity, natural hazards showed a clear negative trend of increment. Data collected from "International Disaster Database" and "United Nations Office for Disaster Risk Reduction" (Guha-Sapir et al. 2015) justifies this statement. In Figure 2, the numbers of disastrous events between 1960 and 2015 were plotted based on the seven regions defined by BRI. The regression analysis clearly showed that the numbers of disaster event increase dramatically from 1960 to 2015. Natural hazards became disasters when they interfere with settlements, infrastructures and other human activities. Therefore, the increased number of disaster events is not only due to the increasing number of hazardous events, but also is related to the rapidly increasing of population and human activities. Especially in mountainous or less developed countries, the unplanned urbanization resulted in extremely vulnerable human settlements.

Total economic losses are strictly related to the numbers of catastrophic events, and these losses for the seven selected regions are shown in Figure 3. Asian countries, in general, suffered more than Europe and Africa. e.g., China lost over 50 billion USD due to natural hazards in the year 2004 only. Economic losses are not only related to the numbers of disasters but also depend on the social and economic status of the countries. Studies on the global expected annual mortality risk due to natural hazards showed that regions along the Belt and Road will experience much higher mortality compared with the global average (Shi et al. 2016).

As most of the BRCs are developing or less 
developed countries, the statistic also shows that the average economic loss against GDP for BRCs is twice more than the world average (Figure $3 \mathrm{~b}$ ). Therefore, the threat imposed by natural hazards to BRCs is worse than the rest of the world.

\section{Examples of Natural Hazards in BRC}

Among many severe disasters occurred in recent years in the BRCs and particularly in central Asia, some of the most significant events are described below to illustrate the great variety of natural hazards affecting the areas and the relevant impact on infrastructures and civil society. The very existing of those natural hazards generated increasing demands on the effective disaster risk reduction and therefore brought scientists from different countries together at this international

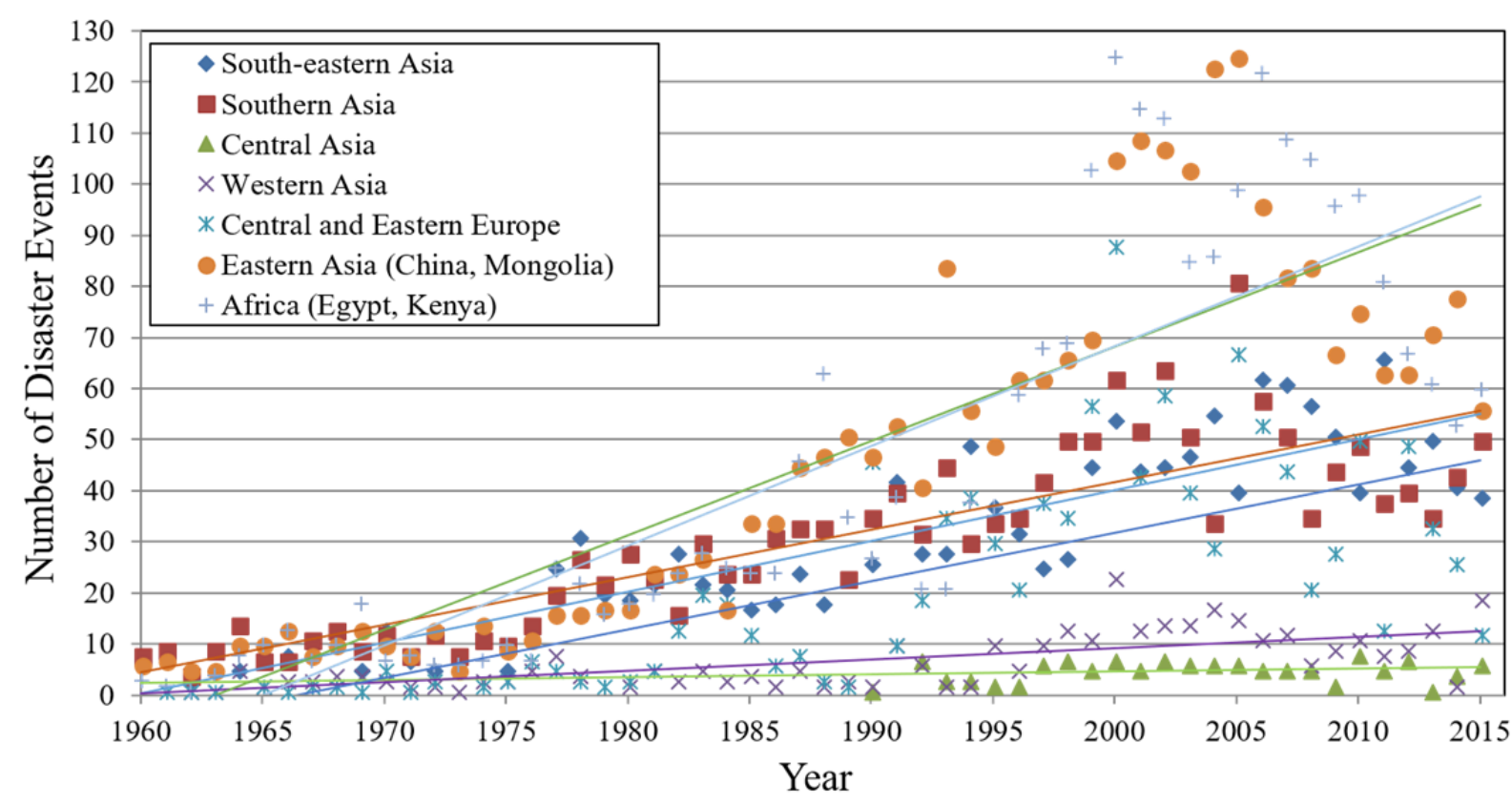

Figure 2 Trend of natural disasters (Source: EM-DAT). Natural disasters include geophysical, meteorological, hydrological and climatological disasters. Disaster events shown in this figure must satisfy at least one of the following criteria: 1.10 or more people dead; 2. 100 or more people affected; 3 . The declaration of a state of emergency; 4 . A call for international assistance.
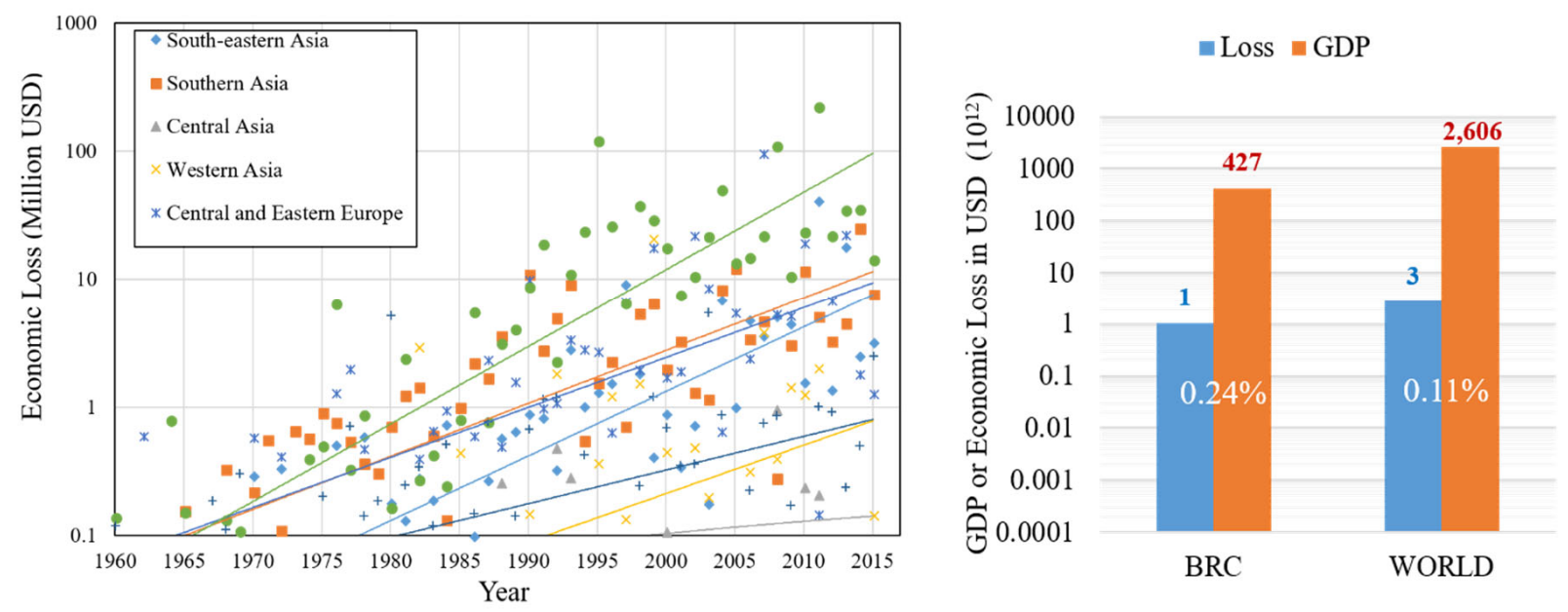

Figure 3 Economic loss caused by natural hazards in Belt and Road Countries (BRCs). a) Economic loss for each region of BRCs (Left); b) The economic loss against GDP for BRC and world average level (Right) (Data Source: EMDAT). 
workshop.

\subsection{Landslide along Karakoram Highway (KKH), Pakistan}

The China-Pakistan Economic Corridor (CPEC) is a strategic project between China and Pakistan with relevant economic, cultural, historical and geopolitical significance. The CPEC aims to connect the Pakistani port of Gwadar with the Chinese city of Kashgar through a road and railway network of around $3000 \mathrm{~km}$. However, this ambitious project is hampered by frequent disruptions due to geological hazards along the route in northern Pakistan and mountainous region of China (Figure 4). Among these hazards, the most frequent and devastating are landslides which severely affected the only route connecting the province of GilgitBaltistan with China (Derbyshire et al. 1996; Hewitt 2009). The frequent land-sliding in the region can be mainly related to the abundance of unconsolidated, highly weathered and fractured geological formations; well-developed rock discontinuities because of the active tectonics, frequent earthquakes, uncontrolled blasting for construction and repair of the roads, presence of the largest glaciers out of the polar regions, precarious locations of alluvial, lacustrine and moraine deposits; severe climatic conditions leading to rapid weathering, poor drainage conditions, scarcity of vegetation, high rates of erosion and anthropogenic activities on unstable slopes (Derbyshire et al. 2001; Kamp et al. 2008; Panzera et al. 2015; Shafique et al. 2016).

The recent example of such events, is the Attabad landslides on $4^{\text {th }}$ January 2010 that blocked the river Hunza, killing 20 people, displacing 6000 and forming a natural lake of 9 miles which still exists and submerging $19 \mathrm{~km}$ of KKH (Figure 5a). The landslide dam had a height
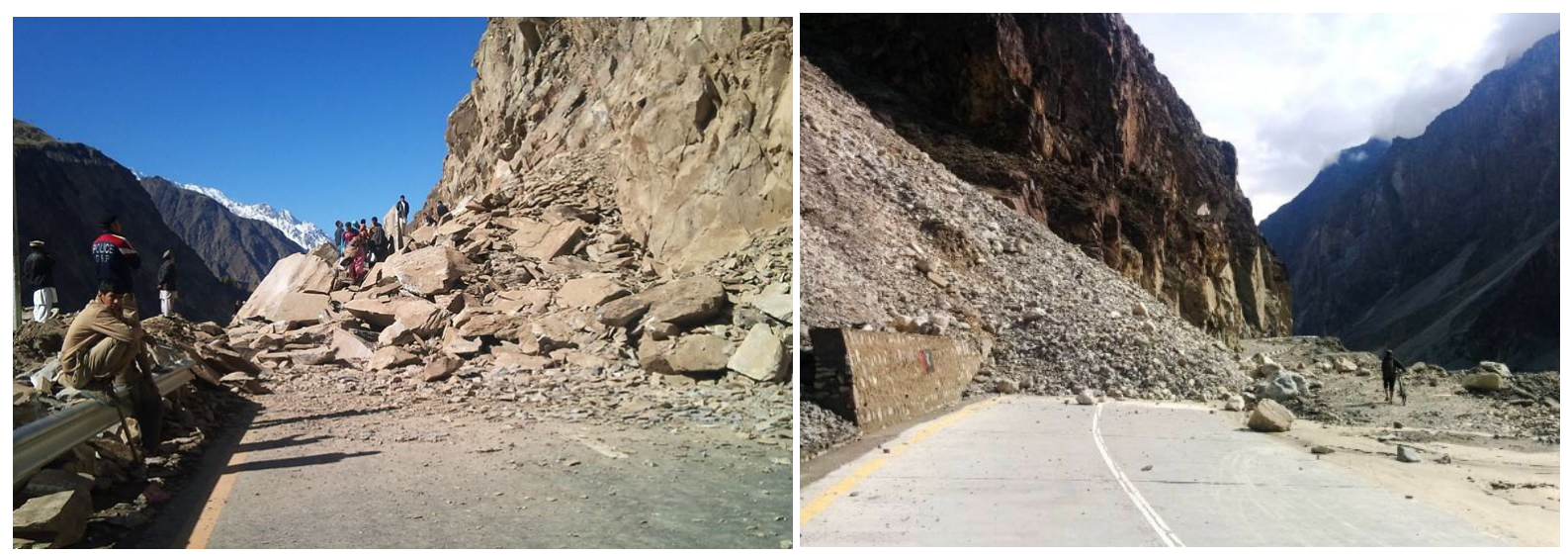

Figure 4 Geo-hazards along China-Pakistan Economic Corridor. a. Landslide on Karakorum highway (Left) (March 2016); b. Landslide on Karakorum highway (Right) (April 2016) (Source: Tayyeb Akram 2016).
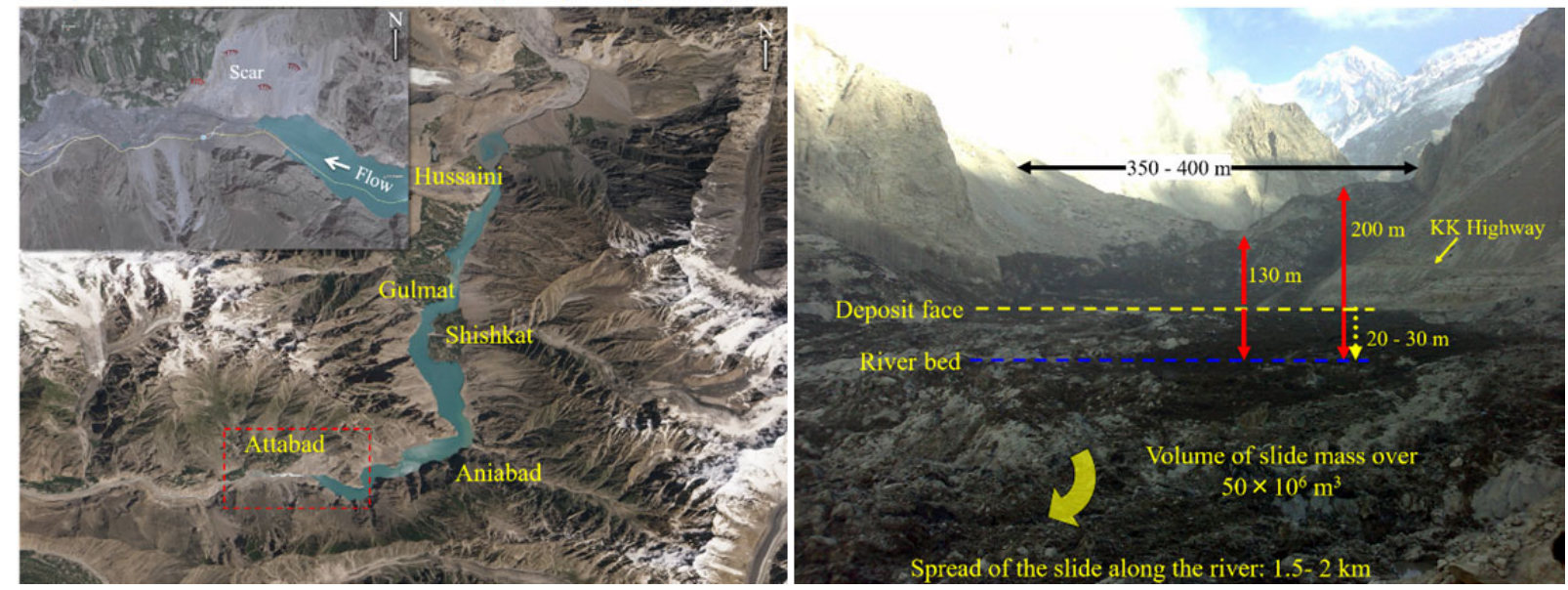

Figure 5 Attabad landslide dammed lake at Pakistan. a. Satellite imagery on August, 2010 showing blocked Hunza River and the growing lake (Left); b. The landslide dam (Right) (Source: Muhammad Jamil 2016). 
of $130 \mathrm{~m}$ to $200 \mathrm{~m}$ and a width of $350 \mathrm{~m}$ to $400 \mathrm{~m}$. The length of this dam was about $2 \mathrm{~km}$ along the river. The overall volume estimated was over 50 million $\mathrm{m}^{3}$ (Figure $5 \mathrm{~b}$ ). On $14^{\text {th }}$ September 2015, Prime Minister of Pakistan inaugurated the realigned portion of $\mathrm{KKH}$ containing five tunnels with $7 \mathrm{~km}$ in length on the whole. The realignment project was completed at the cost of 275 million dollars and restored the road link between Pakistan and China.

\subsection{Gorkha Earthquake, Nepal}

Himalaya is formed due to the collision of the Eurasian and Asian plates and Nepal which lies at the central part of this tectonically active mountain range (Searle et al. 1987). Numerous active faults in the Himalaya are the indicator of recent crustal movements, that are responsible for large earthquakes (Nakata et al. 1982). Nepal experienced devastating earthquakes in 1255, 1810, 1866, 1934, 1980, 1988 (Pandey et al. 1995). The country was hit by a devastating MW 7.8 Gorkha earthquake on 25th April 2015. The epicenter was at Barpak, about $77 \mathrm{~km} \mathrm{NW}$ of Kathmandu. The quake and its subsequent aftershocks were responsible for about 9,000 deaths, 23,000 injuries, and a tremendous damage to the public and private property (MoHA 2015). It became the worst natural disaster that struck Nepal after the
1934 Nepal-Bihar earthquake. This earthquake damaged main highways connecting Nepal and China (Araniko Highway connection Kathmandu with Zhangmu and Pasang Lamu Highway connection Kathmandu with Kerong). Pasang Lamu Highway is in operation at present while Araniko Highway is still not functioning (Regmi et al. 2016). Figure 6a shows a typical session of Araniko Highway suffered from rockfall during the Gorkha earthquake and till 2017 this location only managed to provide temporary road access.

Gorkha earthquake also provided overwhelmed loose material in mountainous region so that inducing secondary hazards such as debris flow and landslide threatening the safety of people's life. Debris flow during rainy season is one of the most severe disaster at this region (Figure 6b). Effective strategies to address the secondary hazard after earthquake and to achieve "build back better" are big challenges that faced by local government. SiDRR will be able to provide a platform to transfer these knowledges and experience we gained after 2008 Wenchuan Earthquake.

\subsection{Coastal Hazards at Galle, Port City in Sri Lanka}

SiDRR deal with ocean disaster since it affected the maritime silk road as shown in Figure 1

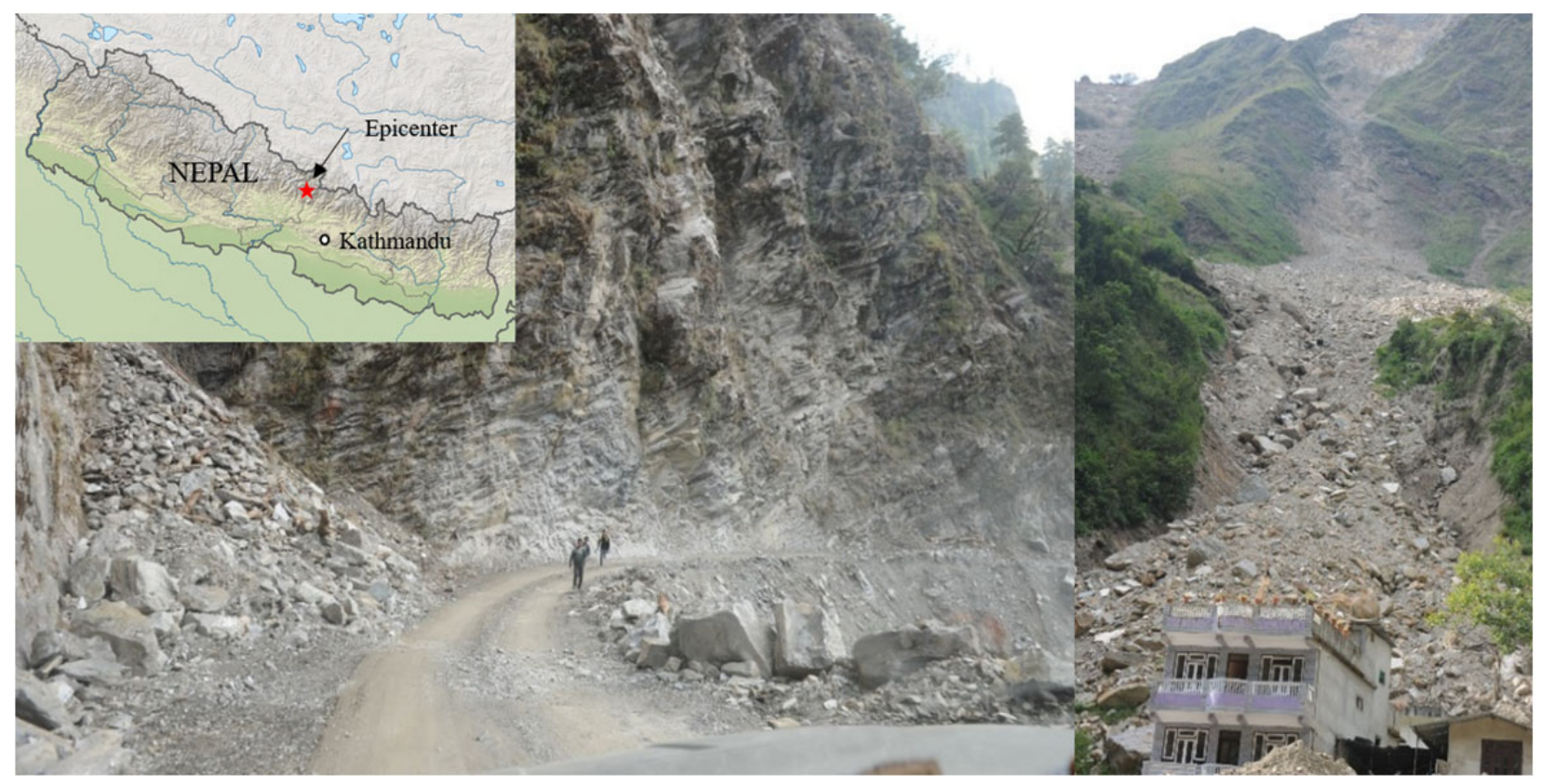

Figure 6 Gorkha earthquake at Nepal on 25 April 2015. a) Rockfall during earthquake at Araniko Highway (Left) (Map from USGS); b) Debris flow during Monsoon season after the earthquake (Right). 
and Sir Lanka is one of the key nodes along it. Type and magnitude of natural hazards affecting Sri Lanka are greatly influenced by the location being the island located in the Indian Ocean (Villagran de Leon 2008). Hydrodynamics of ocean systems are temporally varied from seconds, to hours, to months, to years (Garcin et al. 2008; Strunz et al. 2011). Hence, temporal frequencies of events are highly depended on temporal distribution of the coastal hydrodynamics.

Sri Lanka is characterized by a coast line of $1585 \mathrm{~km}$ in length, covering $64,000 \mathrm{~km}^{2}$ terrestrial land mass where coastal region encompasses $22 \%$ of the total extent which is quite a significant portion of the land. Out of the 20.48 million population, $32 \%$ are living along the coastal belt which includes $65 \%$ of the urban area. With respect to the infrastructure, $41 \%$ of the urban cities built on the coast and four of these cities had a population exceeded 100,000. Further, $80 \%$ of the tourist hotels and two-thirds of all industrial production are based on this region. During the last 25 years, the economic and social conditions as well as the exploitation of resources, grew significantly. By considering the number of people affected by natural hazards during the period of 1974 to 2004, it clearly identifies that droughts (55.5\%), tsunami (27\%), storm and floods (16\%), and landslides (1.2\%) represent the most frequent disasters in Sri Lanka (Department of Census and Statistics 2007).

The 2004 Indian Ocean earthquake occurred at 00:58:53 UTC on 26 December, triggering a series of devastating tsunamis affecting most of the coastal countries, killing 230,000-280,000 people in 14 countries, and inundating coastal communities with waves up to 30 meters (100 ft) high. A significant example of such disaster is the port city in Sri Lanka, Galle ( $6^{\circ} 3^{\prime} 12.66^{\prime \prime} \mathrm{N} ; 80^{\circ} 13^{\prime}$ $\left.15.52^{\prime \prime} \mathrm{E}\right)$, where strategic infrastructures run along the coast and city center within $200 \mathrm{~m}$ from the sea, (e.g., bus terminals, railway station and commercial centers) (UNESCAP-TRATE IOTWS Project 2015).

Galle was subjected to the severe impact of tsunami waves their magnitude having increased due to near-shore transformation processes (Figure 7). The number of persons killed, disappeared, injured and affected is of the order of 500, 90, 1000 and 8120 respectively (Department of Census and Statistics 2007). Houses and other buildings damaged were about 1600 and 1300 respectively. Galle is one of the many coastal cities around the world, which remains heavily exposed to the tsunami hazard (Villagran de Leon 2008). Presence of poorly constructed buildings and inadequate drainage would have contributed towards increased vulnerability. This is a good example of frequency, magnitude and impact of events, which pose a great threat to BRCs countries with the extensive coastal line.

\section{Disaster Risk Reduction on Belt and Road Initiative}

China's policy on continuous investment in the DRR after the Wenchuan earthquake (2008) and the engagement with DRR in the BRCs were seen as important developments under the Sendai Framework for DRR. The promotion of SiDRR project could facilitate the implementation of

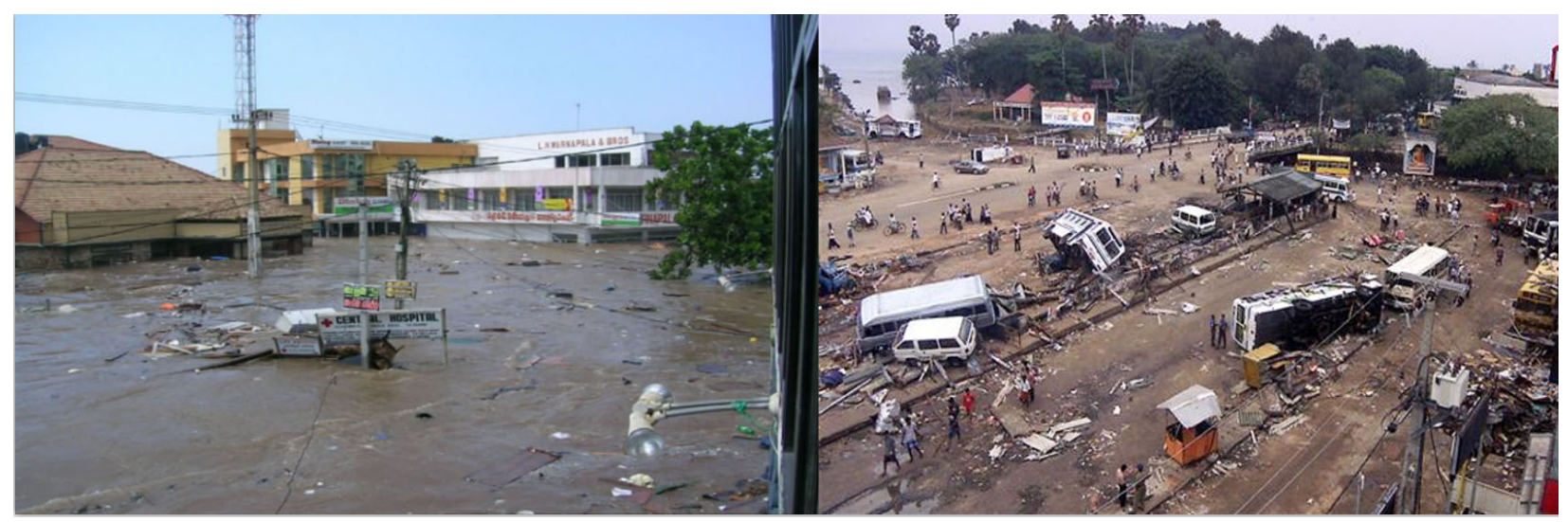

Figure 7 Tsunami at Galle- Coastal cities of Sri Lanka on December 2004. a) Tsunami at Galle (Left); b) Inundated buildings at the heart of the city and devastated bus terminal (Right) (Source: Tilak Priyadarshana 2016). 
Sendai Framework in all BRCs and assist in developing best practices in partner countries on matters related to DRR.

In this international framework, it is important to build a reliable partnership. Natural hazards usually affect the social and economic development of all countries and neighboring countries normally suffer from the same hazard or even trans-boundary hazards. It is, therefore, useful to build a partnership with common issues to face and sharing common interests to carry out risk reduction. In this partnership, joint responding such as joint research on hazard mitigation, a common database of hazard information and academic exchange are expected.

Among the main objectives it can be accounted: the development of major disaster forecast models and disaster risk assessment models which can be applied in the BRCs; the establishment of an acceptable levels of risk from natural hazards and the formulation of early warning protocols; the definition of a disaster risk analysis method and risk management plan which include the potential risk identification, risk evaluation methodology, risk control and management and protection measures for critical infrastructure under the threat of nature hazards.

To achieve the goals of our project, four major challenges, which however bring with them many opportunities, have to be faced:

(1) Challenge: a major gap is represented by the lack of a common geological and meteorological background on natural hazards along the Belt and Road with few shared information and an unclear coordination mechanism. New monitoring instruments need to be deployed at critical areas for data collection.

Opportunity: Scientists have to work together to gather and share strategic information about past disasters, their characteristics and distribution. A systematic and large-scale database needs to be implemented in order to effectively collect and exchange data which will constitute the foundation of this project.

(2) Challenge: Under climate change, natural hazards show new characteristics in terms of formation, triggering criteria and mobility which are yet not well understood. The dynamic evolution of natural hazards and the future trend need to be studied.
Opportunity: With the active involvement of national meteorological services, long-term data sharing on climate can be possible so recognizing the trend of climate change over the past centuries. This can help in more accurate prediction of the expected climate changes and their effect on the environment and associated hazards.

(3) Challenge: No hazard and risk assessments have been conducted along the Belt and Road. As different countries have different social and economic status, it is a challenge to justify the acceptable risk baseline for different countries.

Opportunity: Hazard and risk assessment can be conducted at both regional and local level of BRCs where no systematic assessments have been done before. The associated experiences and knowledge transfer among involved countries could largely benefit in the improvement of the resilience of the communities at risk. Unresolved issues such as trans-boundary disaster could be coped by the involvement of an international scientific community as well as policy-makers.

(4) Challenge: Design codes, procedure, technologies and practices for hazard assessment and mitigation in different countries largely varies. Mechanisms to deal with the trans-boundary disasters are some of the major challenges that have to be faced.

Opportunity: Hazard mitigation has been carried out in the past decade in BRCs in many different forms. However, code of practice in hazard mitigation is neither well developed nor standardized. This project gives the opportunity to act as a starting point to review and systemize the works already done. Key technologies, good design practices and affordable solutions shall be developed and disseminate to less developed countries and regions.

Besides all the challenges and opportunities, this project can bridge the gap to the Sendai Framework priority actions by sharing some of the framework's goals albeit at a smaller scale and shorter timeframe, such as:

(1) Substantially reduce damage to critical infrastructure and disruption of basic services, among them health and educational facilities, including through developing their resilience by 2030;

(2) Substantially increase the number of countries with national and local disaster risk 
reduction strategies by 2020;

(3) Substantially enhance international cooperation to developing countries through adequate and sustainable support to complement their national actions for implementation of the present Framework by 2030 (UNISDR 2015).

In summary, the Bureau of International Cooperation of Chinese Academy of Sciences emphasized the importance of collaboration between scientists and the local authorities on natural hazards assessment and risk management in BRCs. It was envisioned that the Chinese Academy of Science should play its role as a provider of science and education focusing on prioritized regions and infrastructures and concentrating on improving the livelihood of people in BRCs. Chinese Minister of Science (MOST) highlighted the significance of BRI as a chance for high-level collaboration between science and economic development.

DRR is crucial for the safety of infrastructure construction in BRI and is also an important aspect of the science and technology development as stated in BRI. MOST planned to strengthen the international academic exchange, talent cultivation, collaborated laboratories and science centers, data sharing and multinational projects, hence help the implementation of BRI.

\section{Strategies for Disaster Risk Reduction}

The hazard assessment and risk reduction along the Belt and Road is a key point for the success of the Initiative. As listed before, the risk reduction along the Belt and Road requires: (1) strategic information about past disasters collected in a central archive; (2) long-term data sharing available by the local authorities and institutes; (3) investigations on natural hazards and risk assessment (both ground- and remote-based); (4) shared protocols and guidelines in mitigation practices. The outcomes of SiDRR will influence the decision-making on the actions for managing the disasters risk. The BRI comprises more than 65 countries (Cui et al. 2017). In this context, all the actions carried out for DRR are influenced by the size of the project and limited by the heterogeneity of the countries involved. Therefore, the complexity of DRR is directly related to the size of the study area.

The concept of risk is defined by Varnes (Varnes 1984) as the "number of lives lost, persons injured, damage to property, or disruption of economic activity due to a particular natural phenomenon", therefore the risk is function of the: hazard's probability of occurrence, exposure as the value of the elements present in the hazard zones at risk, and vulnerability (from o to 1) as the specific effect on exposure (Commission Staff Working Paper 2010). Therefore, the risk assessment represents the ending point of the analysis proposed for DRR along BRI. This type of analysis must be preceded by a sequence of different mandatory activities due to the size of the investigated area aimed to obtain the suitable conditions for a correct assessment of natural hazards and related risk. The most demanding preliminary activities are protocols and guidelines defining and dissemination, data collection, data management and susceptibility assessment.

From the modeling point of view, the risk assessment along BRI is affected by four main constraints independent from the selected analysis technique:

(1) availability of data;

(2) heterogeneity of data (e.g. different format, scale, mapped objects, adopted terminology);

(3) difficulties in communications and data exchange;

(4) size of the study area.

In the beginning, physical data from different countries must be collected. Moreover, in order to define possible future scenarios, natural hazards occurred in the past must be recorded and correctly interpreted. For this reason, the inventory of the past and actual events is an essential element for the DRR. The BRCs differ in economic stability and thus in policy or investment for risk reduction. Consequently, the availability of such data is not guaranteed for the entire study area.

Second, the BRI represents an exceptional opportunity for international cooperation. Its focus does not simply reside on the infrastructure development but also on the sharing of transnational policies and coordination of risk reduction strategies. Therefore, to conduct a transboundary analysis for risk assessment, it is necessary to establish standards promoted through guidelines for a common use of terminologies, 
analysis and monitoring methodologies, physical quantities, etc. but also for adoption of the most effective mitigation practices.

All above considered, two different alternatives have been selected:

(1) the aggregation, homogenization, standardization of existing datasets and implementation of lacking data;

(2) the development of a new and unique dataset developed according to shared protocols and validated by the existent datasets.

The best solution cannot be established at priori. It will depend on the different classes of data, on the scale of the analysis and on the type of analysis will be adopted.

To overcome the third constraint, all the analyses will be supported by a central archive, which will be populated by the collected datasets, with the aim to make data freely accessible to the global community of researchers. To complete the data center of BRI, one of the future activities will include the web platform implementation for data upload and download, preliminary filtered and homogenized by ETL (Extract Transform Load) facilities (Vassiliadis et al. 2002).

The last hindrance is represented by the size of the study area which significantly influences the scale of the analysis and the possibility to extensively validate the results by field surveys. Therefore, the analyses will be mainly based on remote sensing techniques with zooming on "hot spots" in case of really dangerous situations. More detailed investigations with ground validation will be therefore carried out to support stakeholders and decision makers.

As described above, different types of natural hazards affect BRCs, so in the first phase of SiDRR four types of them are considered: geophysical, geo-hydrological, coastal and climatological hazards. Each of them needs proper technical and methodological requirements to assess the risk associated. Therefore, from the numerical point of view, it is impossible to determine a unique model for hazard assessment which can be influenced by numerous factors (Commission Staff Working Paper 2010) and the scale of work depends on the type hazard took into consideration.

In order to mitigate the negative impact of the expected datasets heterogeneity, the size of the area and the other limits described above, a preliminary 'Tiers' multi-scale susceptibility assessment to evaluate the area most susceptible to specific natural hazards will be carried out. The susceptibility analysis will identify the past and present events without estimation of the frequency. An example of the multi-scale landslide susceptibility assessment was conducted by Hervás et al. (2007) at European scale. The idea gradually increases the scale of the analysis according to consecutive Tiers focusing on specific hotspot study areas. The smallest scale (Tier 1) delineates the priority for the most susceptible regions and exploits low-resolution data. By reducing the area of interest according to the outcomes of the first susceptibility mapping, the Tier 2 assessment can be conducted to detail the susceptibility analysis in priority areas on the base of rose resolution data (Günther et al. 2013). The final susceptibility map will represent the principal hot spots along the Belt and Road. Consequently, the risk assessment will be conducted in the highlighted areas.

\section{Future Perspectives}

The Vision and Act of BRI have attracted global attention, while at the same time, called for multinational effect and invoke large demand on disasters risk reduction. In line with recent UN landmark agreements, DRR along the Belt and Road is also one of the most important aspects included on BRI.

Reflecting on the importance of the UN Landmark agreements, particularly the Sendai Framework, the first International Workshop on Natural Hazard Risk Reduction for the Silk Road Economic Belt and the 21st Century Maritime Silk Road was held from the 8th to 9th November 2016 in Beijing, China. The workshop brought over 80 scientists and policy-makers from BRI regions including geologists, geographers, and engineers from 15 countries, three international organizations and three continents, focusing on natural hazard risk reduction. The main purpose of this workshop was to identify the major disasters occurring within $\mathrm{BRC}$ as well as their mitigation measures.

Participants of this workshop were selected from three categories: government sectors, research facilities and enterprises. This workshop proposed to build a preliminary research network 
for hazard assessment and risk reduction. Under this scheme, international hazard reduction organization(IRDR), regional institution (ICIMOD), overseas institution, (CNR-IRPI of Italy, Moscow State University, University of Peshawar, National University of Science and Technology, COMSATS Institute of Information Technology, from Pakistan, Tribhuvan University of Nepal, Institution of Geology of Kyrgyzstan), some domestic institutions (Institute of Mountain Hazard and Environment, Chinese Academy of Science (CAS); Xinjiang Institute of Ecology and Geography, CAS; Institute of Geographic Sciences and Natural Resources Research, CAS; Institute of Remote Sensing and Digital Earth, CAS; Institute of Geophysics ,China Earthquake Administration; Beijing Normal University,) and Private sector (China Road \& Bridge Corporation; China Three Gorges International Corporation) are the main and potential contributors to SiDRR. Based on this partnership, six task forces have been established: seismic disaster group; ocean and meteorological disaster group; geological disaster group; drought and flood disaster group; disaster risk assessment and management group. Each research group consists of experts from different backgrounds and countries but with great potential to work closely together in this project.

Among the main outcomes of this workshop the following points seem to be very important for the future activity:

(1) Understand disasters in BRCs.

(2) Create a natural hazard database and sharing platform for BRCs.

(3) Choose Pakistan-China corridor as the first area to investigate.

(4) Establish a common protocol for data acquisition, analysis, storage, and visualization.

As for the latter, a possible option could be to adopt the INSPIRE Directive aims to create a European Union spatial data infrastructure for the purposes of EU environmental policies and activities which may have an impact on the environment. There are also other initiatives work in the BRCs such as DBAR (Digital Belt and Road Program 2017) which aims to provide earth observation and create big earth data (Guo et al. 2017) to address the environmental and societal challenge in BRCs. Collaboration with DBAR could potentially benefit in creating the natural hazard database of SiDRR.

To better enhance the collaboration and influence of SiDRR, international thematic workshops have been planned for the next 5 years (Table 1) in order to strengthen the joint activities and facilitate the discussion about the key points already mentioned.

The SiDRR project is expected to be a "cooperative environment" which promotes sharing of experiences, improvement of knowledge, circulation of ideas, production of innovative solutions to reduce the impact of natural events on civil society, collaboration with international institutions etc. Therefore, several initiatives have been proposed to achieve such goals, i.e. enhance the collaboration with International Research on Disaster Reduction (IRDR), to provide opportunities to young scientists to participate in training program on DRR where experiences and lessons learnt from the past disaster events and control measures can be disseminated; the foundation of an International Center for Hazard Reduction and Sustainable Development. This center should involve the scientific institutions along the Belt and Road to provide training, promote international research projects and conduct collaborative researches on theoretic and practical problems on DRR. At the same time, it should regularly provide disaster risk analysis reports on the investigated areas, and represent a focal point for national governments, stakeholders and end users for hazard assessment, risk reduction and emergency management.

Table 1 International Symposium of Silk Road Disaster Risk Reduction (SiDRR)

\begin{tabular}{l|l|l} 
Year & Location & The theme of SiDRR Conference \\
\hline 2016 & Beijing, China & $1^{\text {st }}$ International workshop on SiDRR \\
\hline 2017 & Islamabad, Pakistan & $2^{\text {nd }}$ International workshop on SiDRR and CPEC Risk Assessment \\
2018 & Central Asia & $3^{\text {rd }}$ International Workshop on SiDRR - extreme climate and drought hazards reduction \\
& Beijing, China & $1^{\text {st }}$ International Symposium on SiDRR and Sustainable Development \\
2019 & Sri Lanka & $4^{\text {th }}$ International Workshop on SiDRR - storm surge and ocean hazards reduction \\
2020 & Beijing, China & $2^{\text {nd }}$ International Symposium on SiDRR and Sustainable Development
\end{tabular}




\section{Acknowledgement}

This work is supported by the International partnership program (Grant No. 131551KYSB20160002), National Natural Science Foundation Major International (Regional) Joint Research Project (Grant No. 41520104002) and Science and Technology Service Network Initiative of Chinese Academy of Science (Grant No. KFJSTS-ZDTP-015) and Authors would like to thank

\section{Reference}

Commission Staff Working Paper (2010) Risk Assessment and Mapping Guidelines for Disaster Management. EU, Brussels.

Cui P, Amar DR, Zou Q, et al. (2017) Natural Hazards and Disaster Risk in One Belt One Road Corridors. In: Advancing Culture of Living with Landslides - Volume 2 Advances in Landslide Science. pp 1155-1164.

https://doi.org/10.1007/978-3-319-53498-5_131

Department of Census and Statistics (2007) Report on Census of Buildings and People Affected by the Tsunami-2004. Colombo, Sri Lanka. Department of Census and Statistics. (http://www.statistics.gov.lk/tsunami/, assessed on 2017-0214)

Derbyshire E (1996) Quanternary and glaccial sediments, glaciation style, climate and uplift in the Karakoram and northwest himalaya: review and speculations. Environemental Changes in the Tibetan Plateau and surrounding Areas. In: Paleogeography, Paleoclimatology, Palaeoecology. E. Derbshire. pp 147-157.

Derbyshire E, Fort M, Owen LA (2001) Geomorphological hazards along the Karakoram Highway: Khunjerab Pass to the Gilgit River, Northern Pakistan. Erdkunde 55: 49-71. (http://www.jstor.org/stable/25647347, assessed on 201702-14)

Guha-Sapir D, Below R, Hoyois P (2015) EM-DAT: The CRED/OFDA International Disaster Database. Université Catholique de Louvain, Brussels, Belgium.

(https://www.emdat.be/, assessed on 2016-11-11)

Digital Belt and Road Program (DBAR) (2017) DBAR Science Plan: An International Science Program for Sustainable Development of the Belt and Road Region Using Big Earth Data. (http://go.nature.com/2evoxcj, assessed on 2017-02-14)

Elisseeff V (1998) The silk roads: Highways of culture and commerce. Berghahn Books.

Garcin M, Desprats JF, Fontaine M, et al. (2008) Integrated approach for coastal hazards and risks in Sri Lanka. Natural Hazards and Earth System Sciences 8: 577-586. (https://hal.archives-ouvertes.fr/hal-00406929, assessed on 2017-02-14)

Guo HD (2017) Big Earth data: A new frontier in Earth and information sciences. Big Earth Data 1(1-2): 4-20. https://doi.org/10.1080/20964471.2017.1403062

Günther A, Reichenbach P, Malet JP, et al. (2013) Tier-based approaches for landslide susceptibility assessment in Europe. Landslides 10: 529-546.

https://doi.org/10.1007/s10346-012-0349-1

Hervás J (2007) Guidelines for mapping areas at risk of landslides in Europe. Institute for Environment and Sustainability Joint Research Centre, Italy. https://doi.org/10.2788/63147

Hewitt K (2009) Catastrophic rock slope failures and late Quaternary developments in the Nanga Parbat-Haramosh all participants of the 1st international workshop for sharing their knowledge and experiences.

\section{Electronic supplementary material:}

Supplementary materials (Appendix 1) are available in the online version of this article at https://doi.org/10.1007/s11629-018-4842-4
Massif, Upper Indus basin, northern Pakistan. Quaternary Science Reviews 28(11-12): 1055-1069.

https://doi.org/10.1016/j.quascirev.2008.12.019

Hewitt K (2009) Rock avalanches that travel onto glaciers and related developments, Karakoram Himalaya, Inner Asia. Geomorphology 103(1): 66-79.

https://doi.org/10.1016/j.geomorph.2007.10.017

Kamp U, Growley BJ, Khattak GA, et al. (2008) GIS-based landslide susceptibility mapping for the 2005 Kashmir earthquake region. Geomorphology 101(4): 631-642. https://doi.org/10.1016/j.geomorph.2008.03.003

Liu W (2015) Scientific understanding of the Belt and Road Initiative of China and related research themes. Progress in Geography 34(5): 538-544. https://doi.org/10.11820/dlkxjz.2015.05.001

Liu W, Dunford M. (2016) Inclusive globalization: unpacking China's Belt and Road Initiative. Area Development and Policy 1(3): 323-340.

Ministry of Home Affairs (MoHA), Government of Nepal (2015) (http://www.moha.gov.np/, assessed on 2017-02-14)

Muhammad Jamil (2016) Presentation: Natural Hazards along the China-Pakistan Economic Corridor (CPEC) and Mitigation Measures, $1^{\text {st }}$ international workshop of SiDRR. Beijing, China.

National Development and Reform Commission, Ministry of Foreign Affairs, Ministry of Commerce of China (2015) Vision and actions on jointly building Silk Road Economic Belt and 21st-century maritime Silk Road. Beijing, China: Foreign Languages Press.

Nakata T (1982) A photogrametric study on active faults in the Nepal Himalayas. Journal of the Nepal Geological Society 2: 67-80.

Panzera F, Lombardo G, Monaco C, et al. (2015) Seismic site effects observed on sediments and basaltic lavas outcropping in a test site of Catania, Italy. Natural Hazards 79(1): 1-27. https://doi.org/10.1007/s11069-015-1822-7

Pandey MR, Tandukar RP, Avouac JP, et al. (1995) Interseismic strain accumulation on the Himalayan crustal ramp (Nepal). Geophysical Research Letters 22(7): 751-754. https://doi.org/10.1029/94GLo2971

Regmi AD, Dhital MR, Zhang J, et al. (2016) Landslide susceptibility assessment of the region affected by the 25 April 2015 Gorkha earthquake of Nepal. Journal of Mountain Science 13(11): 1941-1957. https://doi.org/10.1007/s11629-015-3688-2

Shafique M, van der Meijde M, Khan MA (2016) A review of the 2005 Kashmir earthquake-induced landslides; from a remote sensing prospective. Journal of Asian Earth Sciences 118: 6880.

https://doi.org/10.1016/j.jseaes.2016.01.002

Searle M, Windley B, Coward M, et al. (1987) The closing of 
Tethys and the tectonics of the Himalaya. Geological Society of America Bulletin 98: 678-701.

https://doi.org/10.1130/o016-7606(1987)98<678:TCOTAT $>2$. o.CO;2

Strunz G, Post J, Zosseder K, et al. (2011) Tsunami risk assessment in Indonesia. Natural Hazard and Earth System Sciences 11: 67-82. https://doi.org/10.5194/nhess-11-67-2011 Shi P, Yang X, Xu W (2016) Mapping global mortality and affected population risks for multiple natural hazards. International Journal of Disaster Risk Science 7(1): 54-62.

https://doi.org/10.1007/s13753-016-0079-4

Tayyeb Akram (2016) Presentation: Natural Hazards Along China-Pakistan Economic Corridor, 1st international workshop of SiDRR. Beijing, China.

Tilak Priyadarshana (2016) Presentation: Risk Assessment and Mitigation Within a Tsunami Forecasting and Early Warning Framework: A Case Study of Galle Port City, 1st international workshop of SiDRR. Beijing, China.

UNESCAP-TRATE IOTWS Project (2015) Risk Assessment and Mitigation within a Tsunami Forecasting and Early Warning
Framework Case Study-Port City of Galle. p 77

UNISDR (United Nations International Strategy for Disaster Reduction). (2015) Sendai framework for disaster risk reduction 2015-2030.

(http://www.wedrr.org/uploads/Sendai_Framework_for_Disas ter_Risk_Reduction_2015-2030.pdf, assessed on: 2016-11-11)

United Nations, General Assembly, Transforming Our World: The 2030 Agenda for Sustainable Development, A/69/L.85 (12 August 2015). (www.un.org, assessed on: 2017-1-22)

Varnes DJ (1984) Landslide hazard zonation: a review of principles and practice. UNESCO.

Vassiliadis P, Simitsis A, Skiadopoulos S (2002) Conceptual modeling for ETL processes. Presented at the Proceedings of the $5^{\text {th }}$ ACM international workshop on Data Warehousing and OLAP, ACM. pp 14-21.

https://doi.org/10.1145/583890.583893

Villagran de Leon JC (2008) Rapid assessment of potential impacts of a tsunami: Lessons learnt from the port of Galle in Sri Lanka. No.9, SOURCE Publication Series of UNU-EHS, Bonn. p 96. 